\title{
Ectopic pregnancy with levonorgestrel-releasing intrauterine device in situ: A case report
}

\author{
Ana Rita Simões Carvalho, Alina Seixas, Andrea Quintas, \\ Cristina Godinho, João Gonçalves
}

\begin{abstract}
Introduction: Ectopic pregnancy in the presence of an intrauterine device is a rare phenomenon. When compared with copper device, the levonorgestrel intrauterine system appears to be more protective against ectopic pregnancies. Few case reports have described ectopic pregnancies. Case Report: A 39-year-old woman with a levonorgestrel-releasing intrauterine device presented at our emergency room complaining of persistent lower abdominal pain and scarce vaginal bleeding. Pelvic ultrasound revealed the intrauterine device properly positioned inside the uterine cavity and the presence of an anexial mass, raising the suspicion of ectopic pregnancy, later confirmed with beta-HCG blood level. She was successfully treated with laparoscopic salpingectomy. Conclusion: An ectopic pregnancy with an in-situ levonorgestrel intrauterine device is a rare occurrence. Early diagnosis is of paramount importance in order to prevent its potential catastrophic consequences. Physicians prescribing this type of intrauterine device should be aware of the possibility of this rare event, as the symptoms produced by a tubal
\end{abstract}

Ana Rita Simões Carvalho ${ }^{1}$, Alina Seixas ${ }^{1}$, Andrea Quintas ${ }^{2}$, Cristina Godinho², João Gonçalves ${ }^{2}$

Affiliations: ${ }^{1}$ Resident, Department of Obstetrics and Gynecology, Centro Hospitalar de Vila Nova de Gaia/Espinho, Vila Nova de Gaia, Portugal; ${ }^{2}$ Assistant, Department of Obstetrics and Gynecology, Centro Hospitalar de Vila Nova de Gaia/Espinho, Vila Nova de Gaia, Portugal.

Corresponding Author: Ana Rita Simões Carvalho, Rua Francisco Sá Carneiro, Vila Nova de Gaia, Portugal, 4400129; Email: anaritascarvalho@gmail.com

Received: 28 January 2018

Accepted: 08 February 2018

Published: 01 March 2018 gestation may easily be mistaken for side effects due to the intrauterine device.

Keywords: Contraception, Ectopic pregnancy, Intrauterine Device, Levonorgestrel

\section{How to cite this article}

Carvalho ARS, Seixas A, Quintas A, Godinho C, Gonçalves J. Ectopic pregnancy with levonorgestrel-releasing intrauterine device in situ: A case report. J Case Rep Images Obstet Gynecol 2018;4:100035Zo8AC2018.

Article ID: 100035Zo8AC2018

$* * * * * * * * *$

doi:10.5348/100035Zo8AC2018CR

\section{INTRODUCTION}

Intrauterine devices (IUD) is one of the most used contraceptive all around the world [1]. The IUD is considered to be safe and one of the most effective methods in preventing pregnancy. Nevertheless, its failure rate is not negligible, leading to unwanted pregnancies and induced abortions [1]. The probability described of first-year pregnancy is approximately 0.6 to $0.8 \%$ for the copper IUD (Cu-IUD) and 0.1 to $0.2 \%$ for the levonorgestrel-releasing system (LNG-IUS) [2]. The literature is relatively sparse for risk factors to IUD failure. A review published in 2001 doesn't find significant results between skills of the staff, uterine position or length of the endometrium and risk of IUD failure. The only significant risks described are the woman's age and copper content of the device [3]. 


\section{EDORIUM Journals}

\section{www.edoriumjournals.com/case-reports/jcrog}

It remains uncertain if pregnancies with an IUD in situ have increased risk for complications, like ectopic pregnancies, miscarriages or chorioamniotitis [4]. There isn't direct evidence of potential teratogenic risk to the fetus due LNG-IUS.

Ectopic pregnancies (EP) account for $1.5 \%$ of all reported pregnancies in western countries, and is a major cause of morbidity and, occasionally, mortality [5].

The most described risk factors for EP are: history of pelvic inflammatory disease, ectopic pregnancy or pelvic surgery, smoking, induction of ovulation and the use of IUDs [5]. It remains unknown if salpingitis associated with IUD use is the possible cause of ectopic pregnancy [5].

In last decades, the incidence of EP has increased, and contraceptive use has been potentially one of the important factors associated with this increase. Pregnancies resulting from contraceptive failure may be more likely to be ectopic [5]. The majority of case reports concerning ectopic pregnancies and IUD use relate to copper IUDs rather than levonorgestrel ones [6].

\section{CASE REPORT}

A 39-year-old caucasian multiparous healthy woman was referred to our emergency room with persistent lower abdominal pain and scarce vaginal bleeding for one day. For 11 months, she had been using a LNG-IUS as a contraceptive, with long periods of amenorrhea. She had no history of prior EP, pelvic inflammatory diseases or previous tubal-uterine surgery, in vitro fertilization or other assisted reproduction procedures. She did not smoke.

On admission, she was haemodynamically stable and complained of a persistent tenderness in her right lower abdominal quadrant. The threads of the LNG-IUS and scarce bleeding were visible on speculum examination. On bimanual examination, the uterus was on nongravid size, and there was cervical tenderness and a palpable mass on right vaginal fornix. Her haemoglobin was 13.6 $\mathrm{g} / \mathrm{dl}$ and quantitative human chorionic gonadotropin level was $36478 \mathrm{mIU} / \mathrm{mL}$.

A two dimensional transvaginal ultrasound revealed no evidence of intrauterine pregnancy, and the LNGIUS was properly positioned inside the uterine cavity, as shown in Figure 1. There was a gestational sac situated on right adnexa containing an embryo measuring 22 $\mathrm{mm}$ with positive heart rate consistent with a nine-week pregnancy (Figure 2). Free fluid in scarce quantity was also noted in the pouch of Douglas.

Emergency laparoscopy was performed. Both the uterus and the left adnexa appeared normal. An unruptured mass on the ampullary portion of the right tube was identified. A right total salphingectomy and left sterilization were done. Blood clots in the pouch of Douglas were removed and peritoneal lavage performed. The LNG-IUS was removed after the procedure.
The postoperative period was uneventful, and she was discharged home on the following day.

Histology of the tube confirmed the presence of a gestational sac containing first-trimester chorionic villi and placental site trophoblast. There were no features suggesting salpingitis and there were no other abnormalities.

Informed consent was obtained from the patient for publication of this case report and any accompanying images.

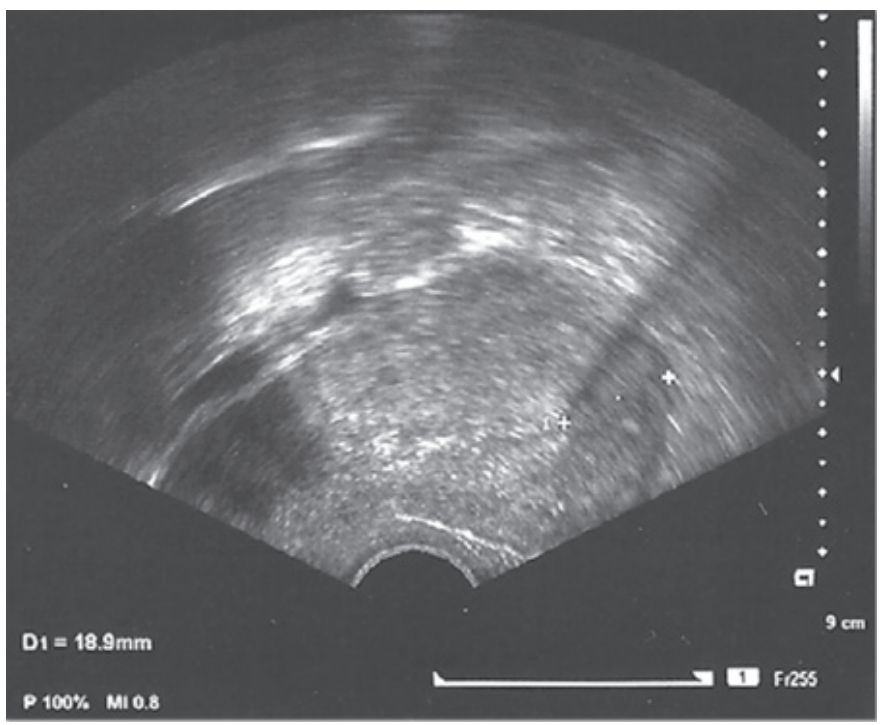

Figure 1: Transvaginal ultrasound of the uterus, showing no evidence of intrauterine pregnancy, and LNG-IUS properly positioned inside the uterine cavity.

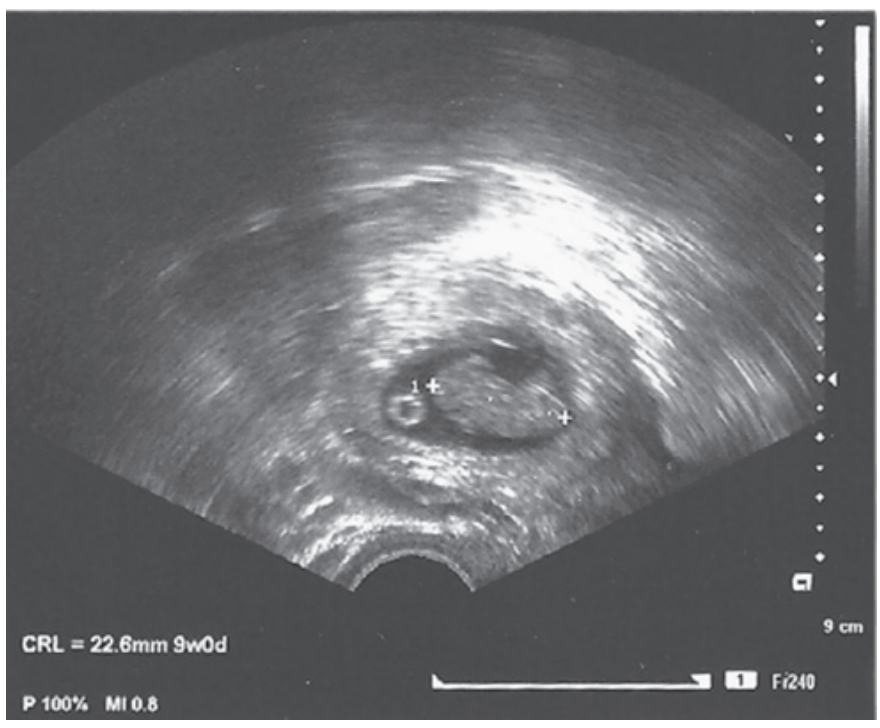

Figure 2: Transvaginal ultrasound showing a gestational sac situated on right adnexa containing an embryo measuring $22 \mathrm{~mm}$ with positive heart rate. 


\section{EDORIUM Journals}

J Case Rep Images Obstet Gynecol 2018;4:100035Zo8AC2018. www.edoriumjournals.com/case-reports/jcrog

Carvalho et al. 3

\section{DISCUSSION}

The rate of ectopic pregnancy after natural conception is $1-2 \%$, and has increased in recent decades. Although ectopic pregnancies during contraception with LNGIUS have been reported previously, the risk of ectopic pregnancy with the use of LNG-IUS has been minimally investigated [5].

Most of the risk factors of ectopic pregnancies are known. The most common include previous ectopic pregnancy, previous tubal surgery, any documented tubal pathology, previous pelvic inflammatory disease, in vitro fertilization with embryo transfer and intrauterine contraceptive device. However, these pre-existing risk factors are present in only around $75 \%$ of the cases [5]. Factors that do not affect ectopic pregnancy risk are previous induced abortion, previous cesarean section and previous oral contraceptive use $[7,8]$.

Almost all of the literature concerning ectopic pregnancies and IUD use relate to copper IUDs rather than levonorgestrel IUDs.

Some studies have demonstrated that a considerable number of ectopic pregnancies occur when a pregnancy occurs while women is on progesterone-only contraceptives, most probably because progesterone decreases smooth muscle activity, limiting the propulsive effect of the tube at the ampullary part [9].

The LNG-IUS used (Mirena ${ }^{\circledR}$ ) is a progesterone-only system containing a total of $52 \mathrm{mg}$ levonorgestrel. Initially, levonorgestrel is released at a rate of approximately 20 $\mu \mathrm{g} /$ day. This rate decreases progressively to half that value after 5 years [10].

The local mechanism by which levonorgestrel enhances contraceptive effectiveness of Mirena ${ }^{\circledR}$ has not been conclusively demonstrated. Studies have suggested several mechanisms that prevent pregnancy: thickening of cervical mucus preventing passage of sperm into the uterus, inhibition of sperm survival, and alteration of the endometrium [10].

Mirena ${ }^{\circledR}$ has been studied for safety and efficacy. According to the information provided by manufacturer, the estimated 12-month pregnancy rates were around 0.2 per 100 women, while the cumulative 5-year pregnancy rate was approximately 0.7 per 100 women. Up to half of pregnancies that occur with Mirena ${ }^{\circledR}$ in situ are ectopic (about 1 ectopic pregnancy per 1000 users per year) [10].

EP can be frequently misdiagnosed at the initial visit despite technological advances. Clinicians always have to evaluate woman who became pregnant while using LNGIUS for ectopic pregnancy. When indicated, laparoscopic salpingectomy is the surgical treatment of choice for tubal $\mathrm{EP}$, with a low rate of surgical complications.

\section{CONCLUSION}

The aim of presenting this case is to emphasize that high-level awareness should be maintained at all times by clinicians. In cases like this, the symptoms produced by a tubal gestation may easily be mistaken for side effects due to the intrauterine device.

\section{REFERENCES}

1. Thonneau PF, Almont T. Contraceptive efficacy of intrauterine devices. Am J Obstet Gynecol 2008 Mar;198(3):248-53.

2. Ganer H, Levy A, Ohel I, Sheiner E. Pregnancy outcome in women with an intrauterine contraceptive device. Am J Obstet Gynecol 2009 Oct;201(4):381. e1-5.

3. Thonneau P, Goulard H, Goyaux N. Risk factors for intrauterine device failure: A review. Contraception $2001 \mathrm{Jul} ; 64(1): 33-7$.

4. Brahmi D, Steenland MW, Renner RM, Gaffield ME, Curtis KM. Pregnancy outcomes with an IUD in situ: A systematic review. Contraception 2012 Feb;85(2):131-9.

5. Walker JJ. Ectopic pregnancy. Clin Obstet Gynecol 2007 Mar;50(1):89-99.

6. Backman T, Rauramo I, Huhtala S, Koskenvuo M. Pregnancy during the use of levonorgestrel intrauterine system. Am J Obstet Gynecol 2004 Jan;190(1):50-4.

7. Kendrick JS, Tierney EF, Lawson HW, Strauss LT, Klein L, Atrash HK. Previous cesarean delivery and the risk of ectopic pregnancy. Obstet Gynecol 1996 Feb;87(2):297-301.

8. Parazzini F, Ferraroni M, Tozzi L, Benzi G, Rossi G, La Vecchia C. Past contraceptive method use and risk of ectopic pregnancy. Contraception 1995 Aug;52(2):93-8.

9. Wånggren K, Stavreus-Evers A, Olsson C, Andersson E, Gemzell-Danielsson K. Regulation of muscular contractions in the human Fallopian tube through prostaglandins and progestagens. Hum Reprod 2008 Oct;23(10):2359-68.

10. Mirena: Product Monograph. Bayer AG. June 2014. [Available at: http://www.mirena.com/html/pdf/ MirenaProductMonograph.pdf]

$* * * * * * * * *$

\section{Author Contributions}

Ana Rita Simões Carvalho - Substantial contributions to conception and design, Acquisition of data, Analysis and interpretation of data, Drafting the article, Revising it critically for important intellectual content, Final approval of the version to be published

Alina Seixas - Substantial contributions to conception and design, Drafting the article, Final approval of the version to be published

Andrea Quintas - Substantial contributions to conception and design, Revising it critically for important intellectual content, Final approval of the version to be published Cristina Godinho - Substantial contributions to conception and design, Revising it critically for important intellectual content, Final approval of the version to be published 


\section{EDORIUM Journals}

J Case Rep Images Obstet Gynecol 2018;4:100035Zo8AC2018.

Carvalho et al. 4 www.edoriumjournals.com/case-reports/jcrog

João Gonçalves - Substantial contributions to conception and design, Revising it critically for important intellectual content, Final approval of the version to be published

\section{Guarantor of Submission}

The corresponding author is the guarantor of submission.

\section{Source of Support}

None

\section{Consent Statement}

Written informed consent was obtained from the patient for publication of this study.

\section{Conflict of Interest}

Authors declare no conflict of interest.

\section{Copyright}

(C) 2018 Ana Rita Simões Carvalho et al. This article is distributed under the terms of Creative Commons Attribution License which permits unrestricted use, distribution and reproduction in any medium provided the original author(s) and original publisher are properly credited. Please see the copyright policy on the journal website for more information.
Access full text article on other devices

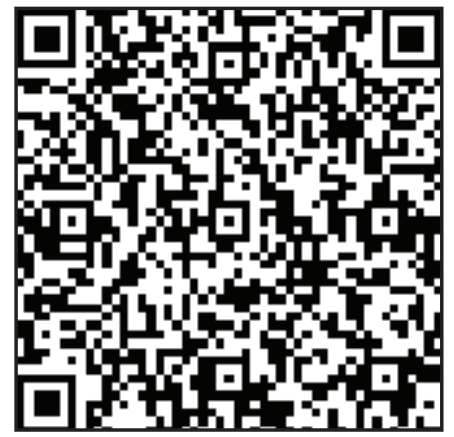

Access PDF of article on other devices

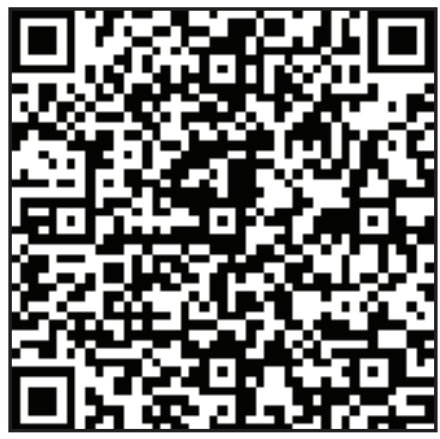

